\title{
DESIGN OF LOW POWER IMPROVED MEDIANFILTER CORE FOR NOISE REDUCTION IN IMAGE
}

\author{
Vinothini $\mathbf{M}^{1}$, Syed Ibrahim $\mathbf{B}^{2}$, A.Kavitha ${ }^{3}$ \\ ${ }^{1} P G$ Scholar, ECE Department, Chettinad College Of Engineering, Karur, India \\ ${ }^{2}$ Senior Assistant Professor, ECE Department, Chettinad College Of Engineering, Karur, India \\ ${ }^{3}$ Professor and Head, ECE Department, Chettinad College Of Engineering, Karur, India
}

\begin{abstract}
In digital image processing, image restoration is a prime factor which is often able to perform some kind of noise reduction on the image. Reduction of impulse or salt \& pepper noise is done by non - linear filtering technique such as the median filter. Here the median filter is designed basically using the comparator and the multiplexer. So, it is essential to develop a new design technique to reduce the power consumption in the median filter. Thereby the comparator and multiplexer used in the median filter is designed using various styles of full adder with help of the cadence 0.18nm technology.
\end{abstract}

Keywords: Multiplexer, Full Adder (FA), Comparator, Power

\section{INTRODUCTION}

Digital images play an important role in various application such as astrononomy, magnitude resonance imaging, mathematical morphology. These images get often corrupted by factors such as channel transmission error, from noisy sensors.Smoothening of these images lead to destroy of edge $\&$ instance details of the images, while sharpening will lead to unwanted intensification of noise.Since the image enhancement through noise cleansing is the fundamental problems in the image processing.So,the depending upon the imagery \& the restorstion technique will make more assumption, this technique is not useful for application.

Thus various filtering method are used depending upon whether the noise is non-additive or not. Linear filtering method fails when the noise is non-additive and not effective in removing impulsive noise in the images. This has given importance to the use of non-liner filtering.

The most commonly used nonlinear filter is the median filter because of its superior and edge preservation compared to linear filters. The block diagram of $n$-bit median filter is shown in figure 1(a) and 1(b)

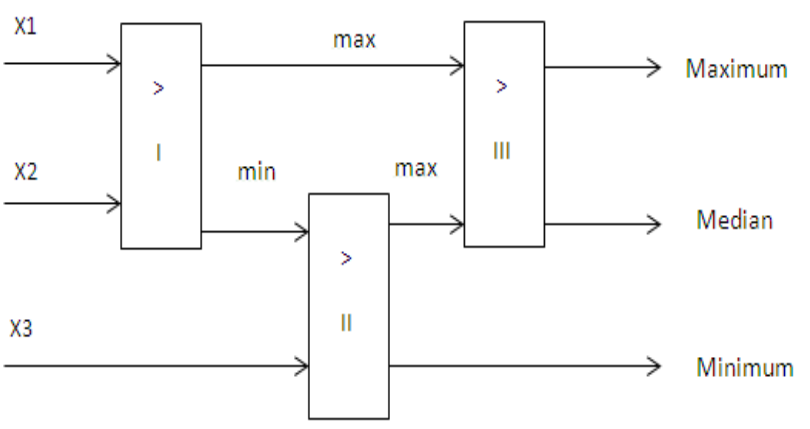

(b)

Fig: 1(a) and (b) : Block Diagram of n-Bit and 3-Bit Median Filter

Here the median filter is designed using comparator and multiplexer. The comparator design is implemented by full adder design which is the basic building block of the many digital VLSI circuits. In this paper, the design technique are implemented using the microwind software. The combination of the comparator and multiplexer which is the basic block of the median filter is shown in figure 2 .

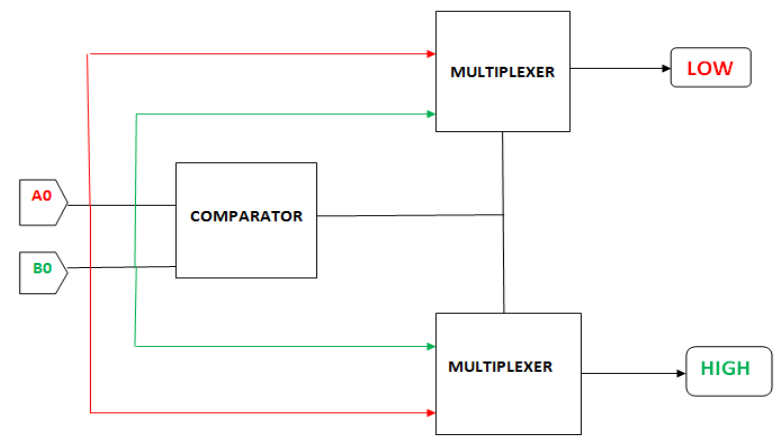

Fig 2: Combination Of Comparator \& Multiplexer 


\section{DESIGN IMPLEMENTATION}

\subsection{Basic Median Filter}

Firstly, discussion about the median's basic block such as the comparator and multiplexer are done. In this paper 3 bit 3input are used where the median value are displayed as output. Here the implementation of the median filter are mainly based on the reduction of the power consumption.
The comparator are implemented using various gates as AND, OR, EX-NOR \& NOT, where the output is given as A>B.The multiplexer are implemented with help of AND, OR \& NOT gates where output are mainly concerned with selection line S0.The basic comparator and multiplexer design used for implementation of basic median filter is shown in figure 3 and figure 4.

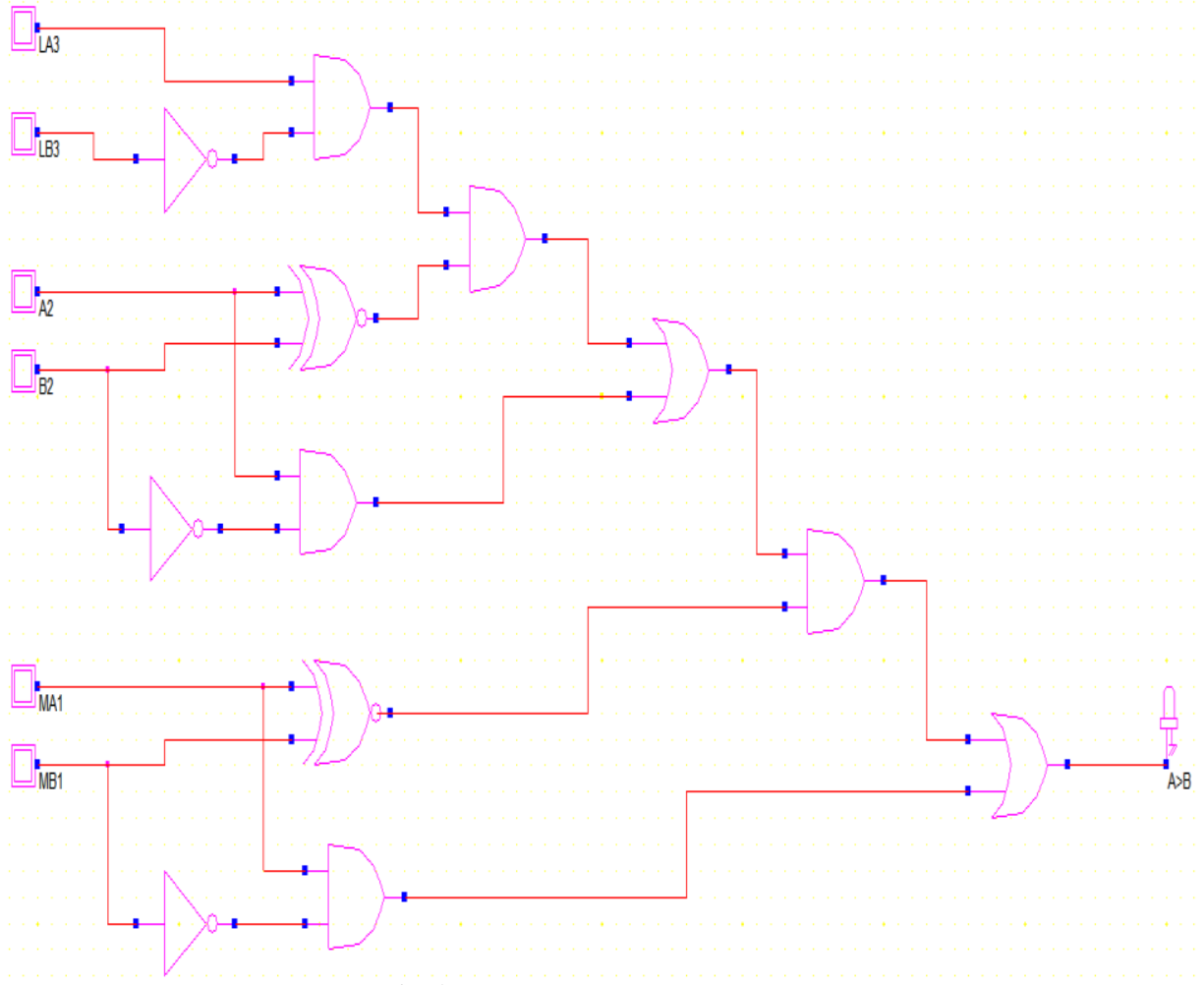

Fig 3: Basic Comparator design

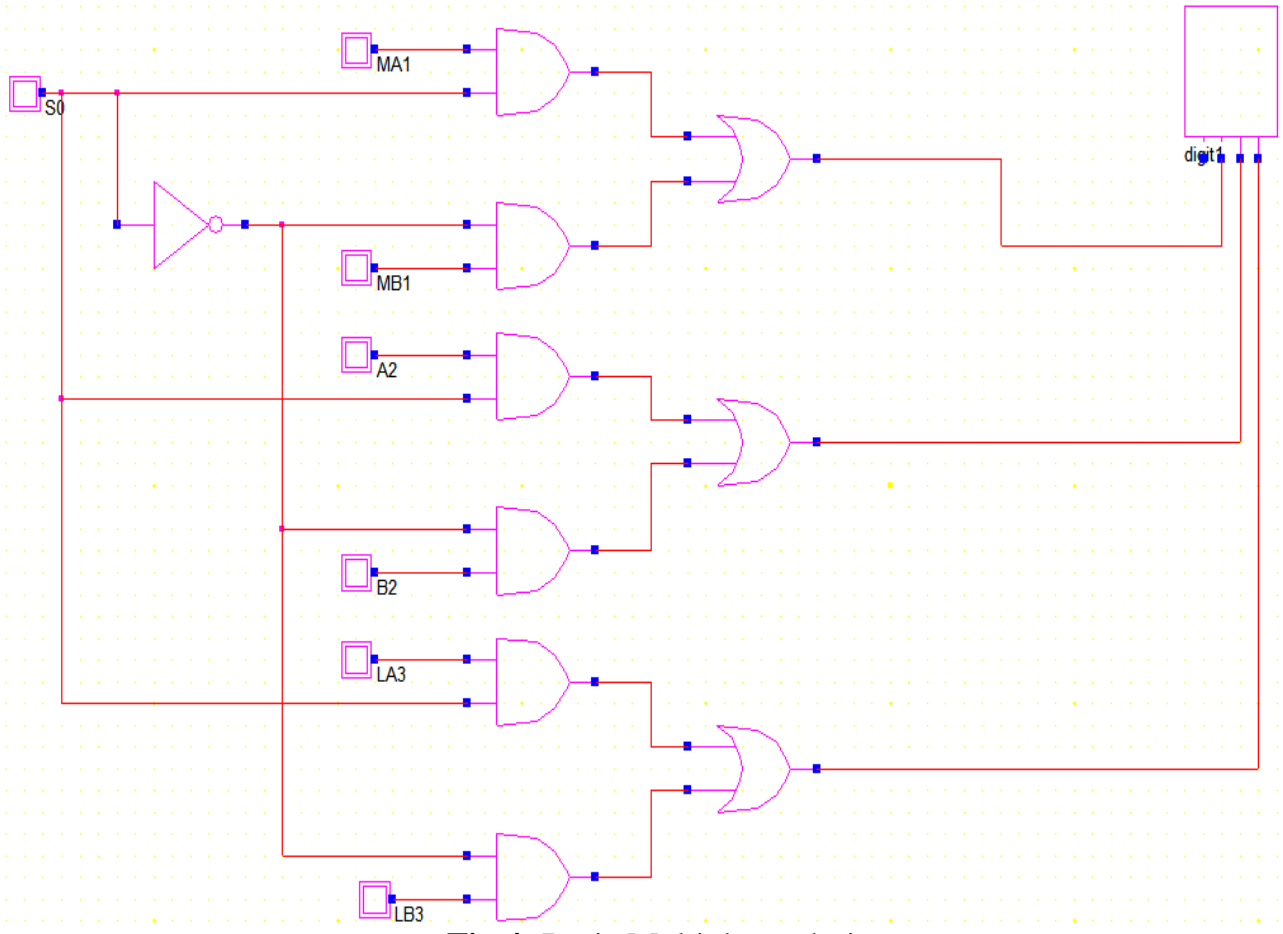

Fig 4: Basic Multiplexer design 
The basic median filter design is shown in figure 5

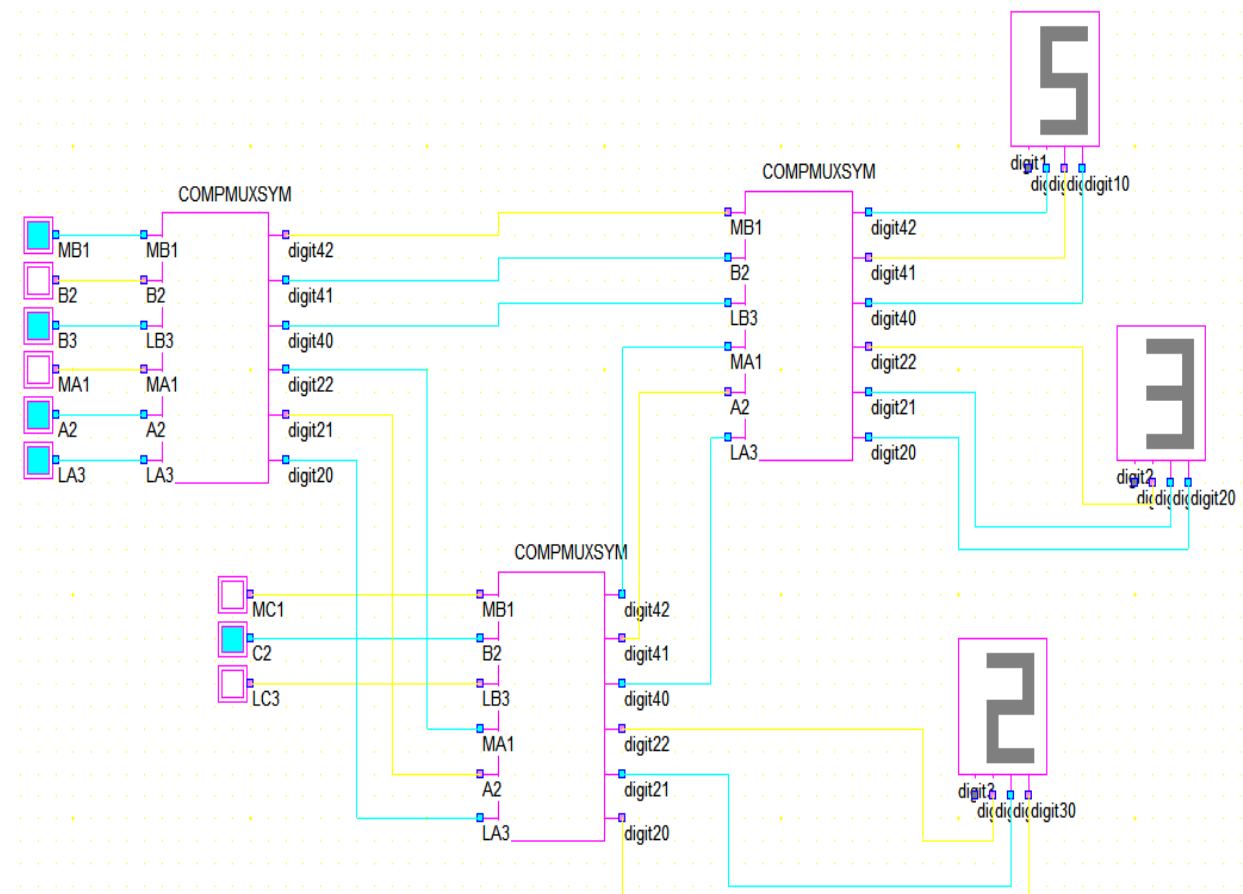

Fig 5: Basic Median filter design

The circuit of the basic median filter integrated using cadence virtuoso platform $0.18 \mathrm{~nm}$ technology is shown in figure 6

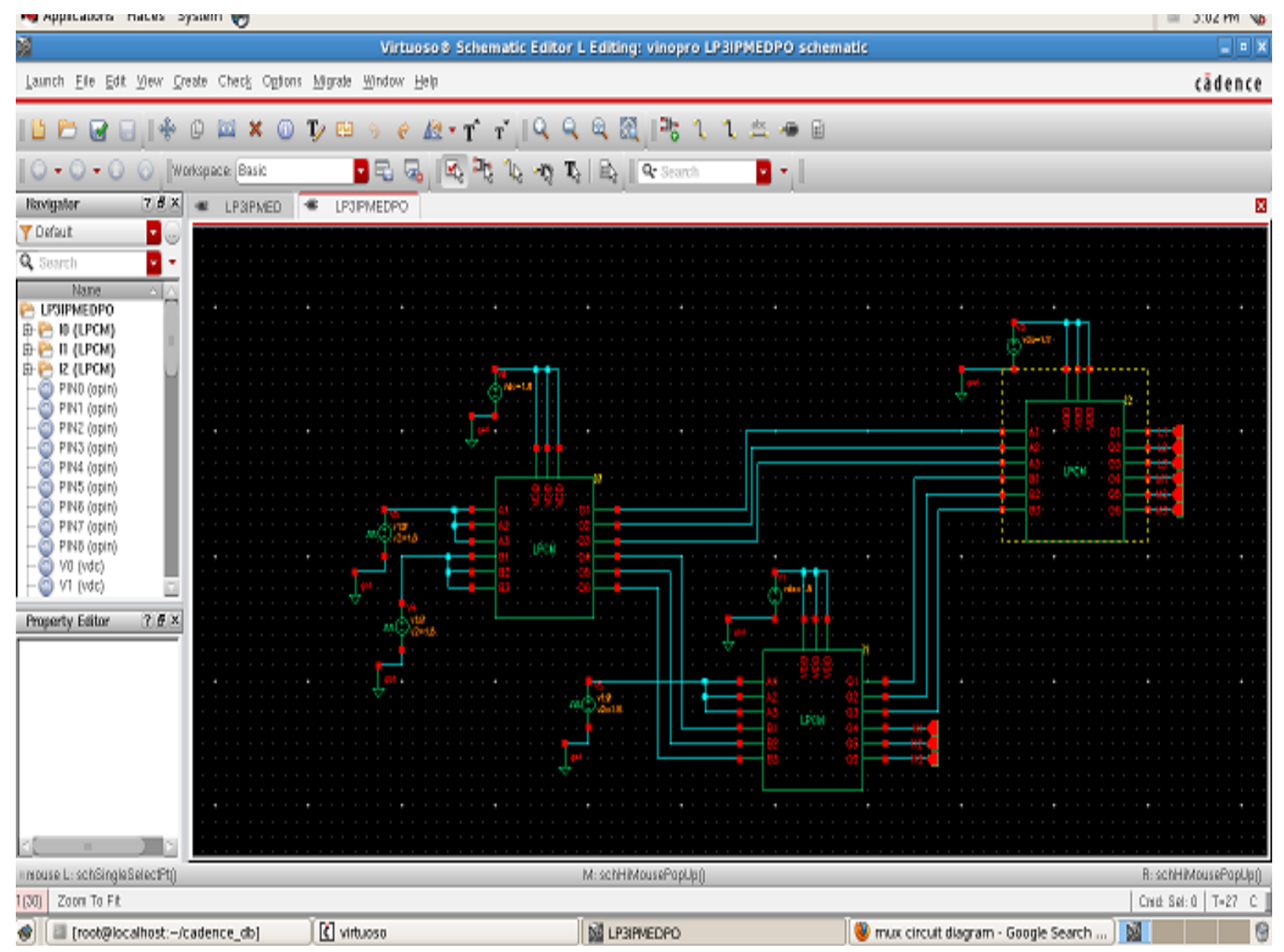


Fig 6: Integration of basic median filter

\subsection{Median Filter using Hybrid Full Adder}

Then another design of low power median filter using hybrid full adder is shown in figure 9 using figure 7 and figure 8 . Here the hybrid full adder design is incorporated in the comparator block which is shown in figure 8

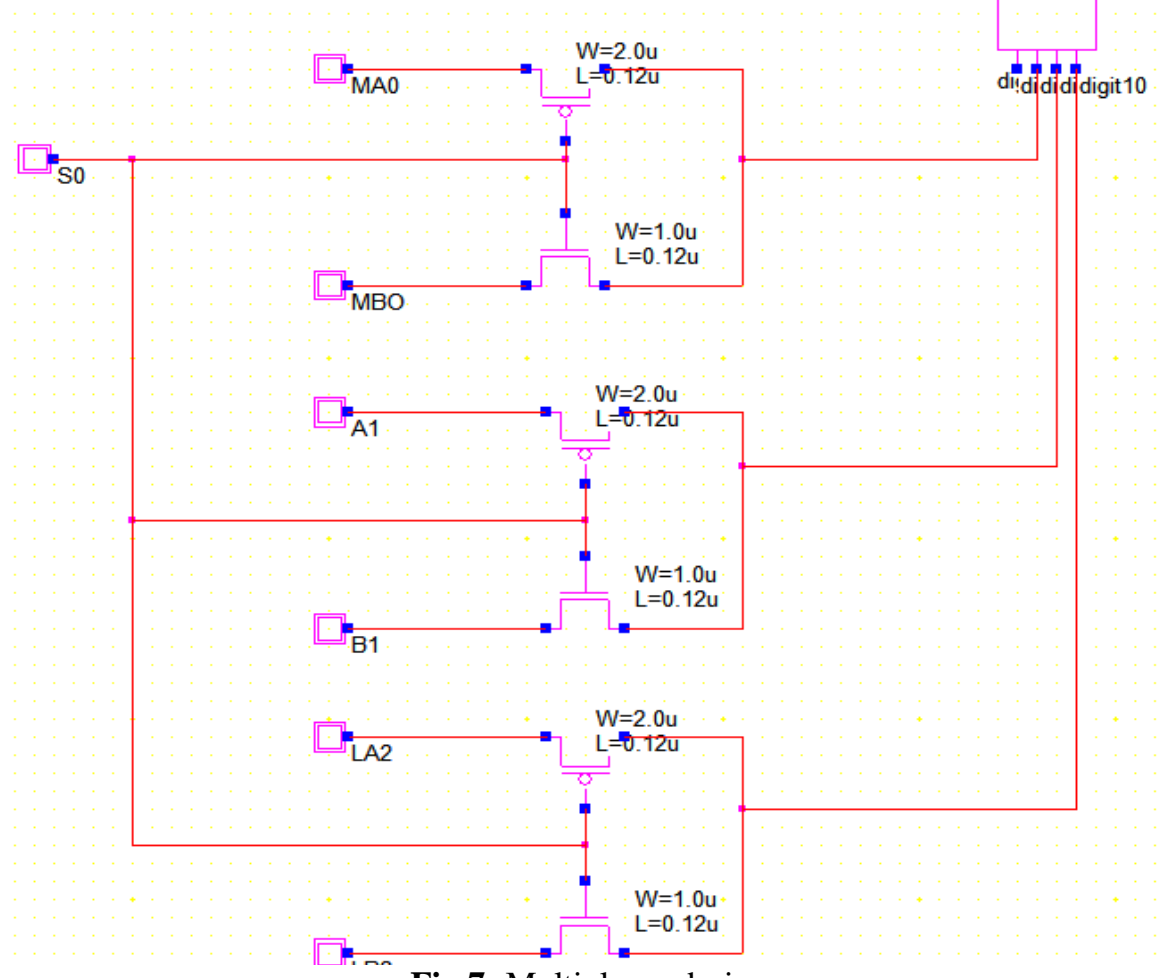

Fig 7: Multiplexer design

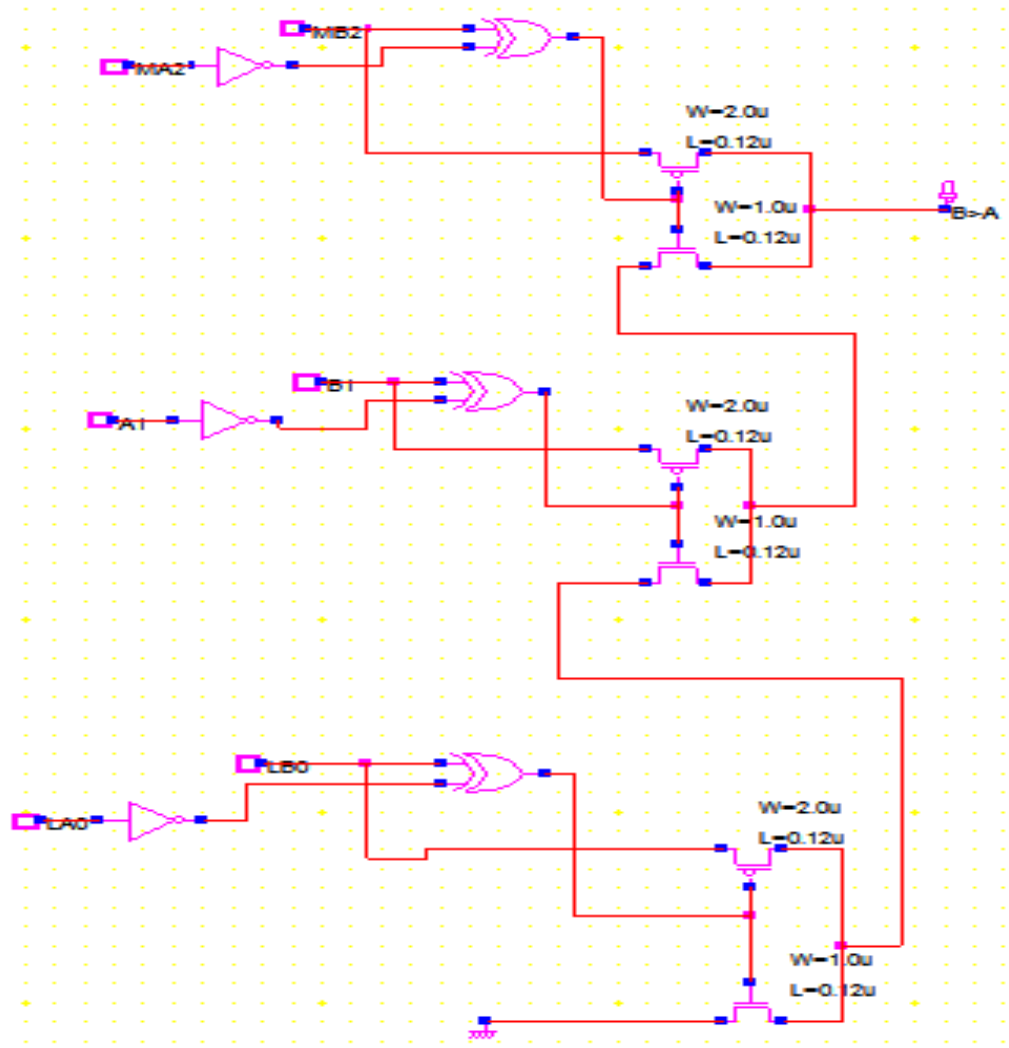

Fig 8: Comparator using hybrid full adder design 


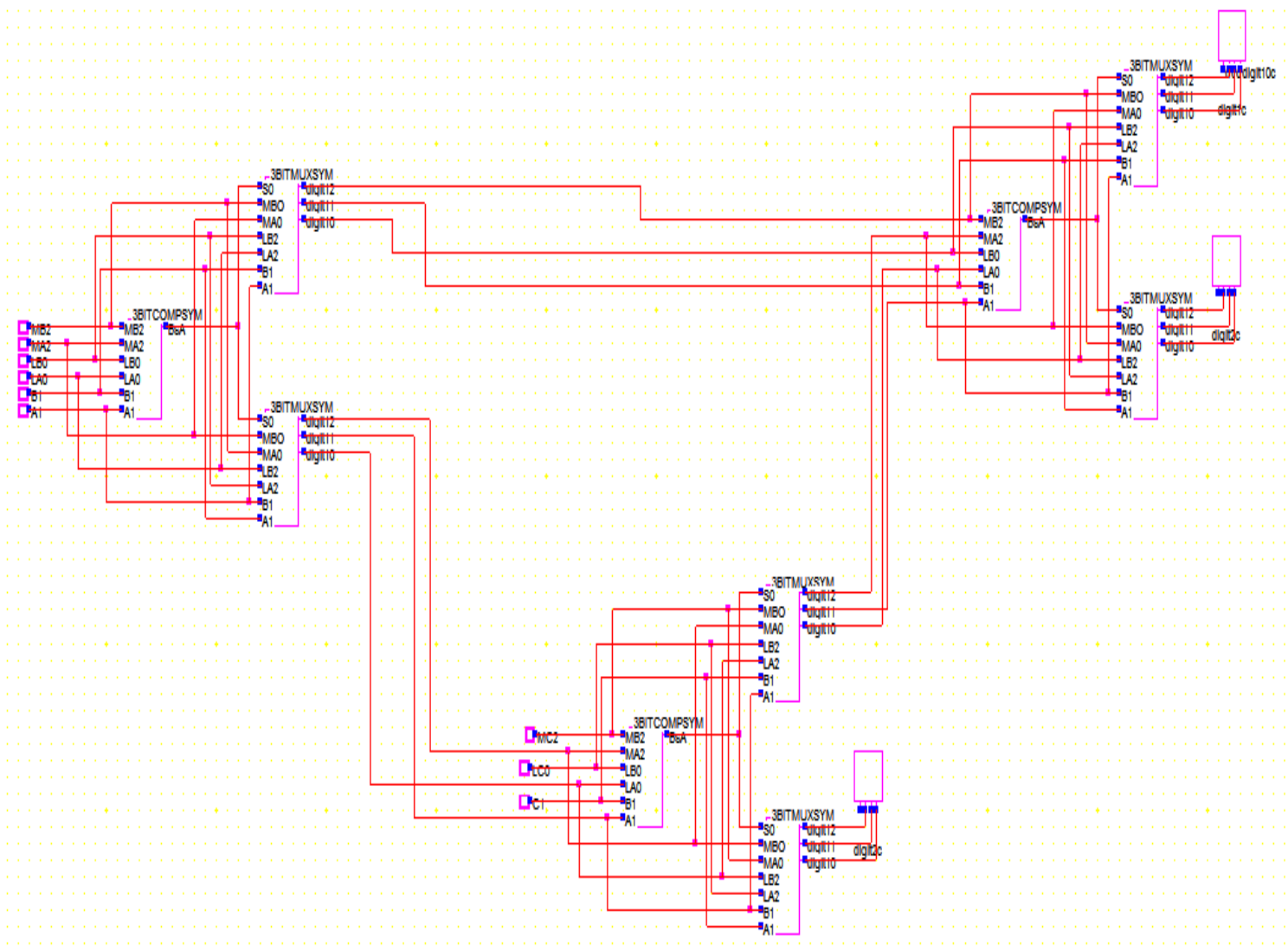

Fig 9: Low Power median filter

The circuit of the median filter using hybrid full adder integrated using cadence virtuoso platform $0.18 \mathrm{~nm}$ technology is shown in figure 10

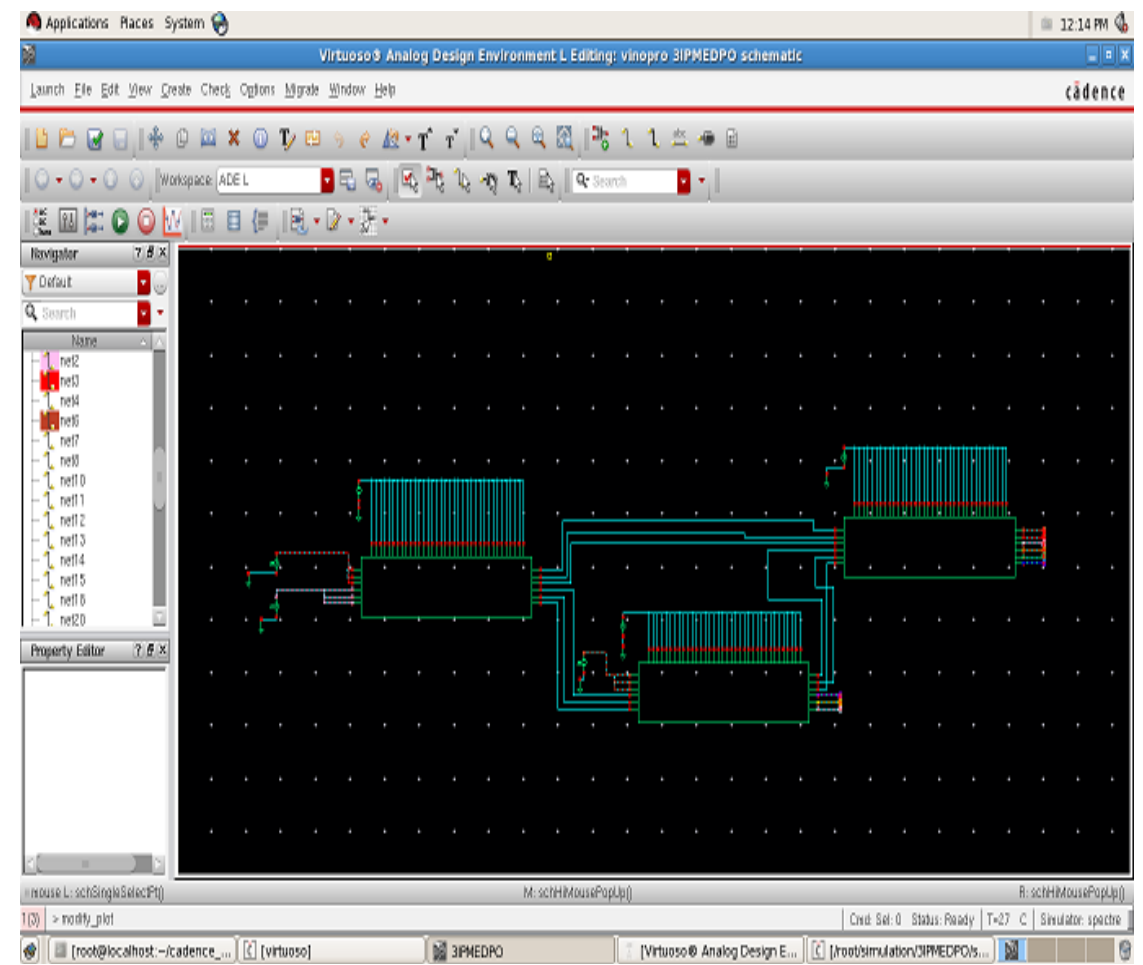

Fig 10: Integration of median filter using hybrid full adder 


\subsection{Median Filter using 6T Full Adder}

The median filter design using the hybrid full adder consumes less power compared to the basic median filter. But it doesn't show much variation in power consumption, only slight variation is observed. So, that the median filter is designed using the $6 \mathrm{~T}$ full adder design. The $6 \mathrm{~T}$ full adder design is shown in figure11, which is incorporated in comparator design shown in figure12.

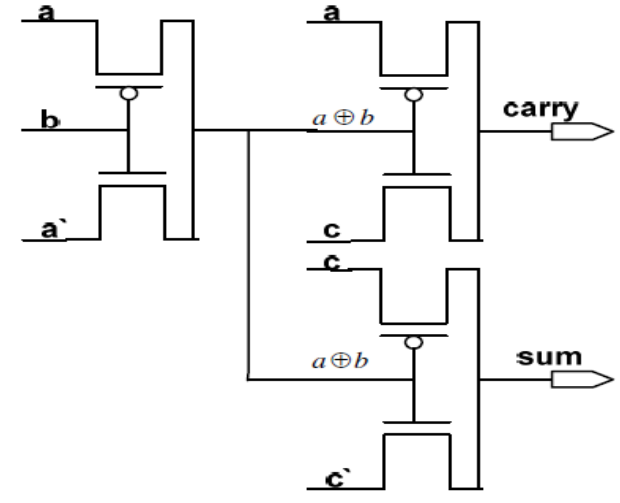

Fig 11: $6 \mathrm{~T}$ full adder

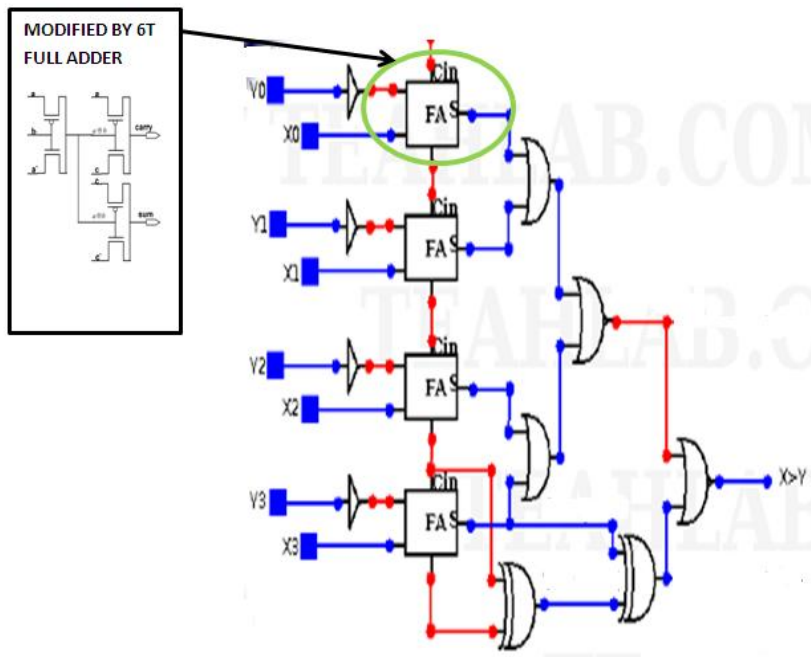

Fig 12: Comparator using 6T full adder design

The circuit of the median filter using $6 \mathrm{~T}$ full adder integrated using cadence virtuoso platform $0.18 \mathrm{~nm}$ technology is shown in figure 13

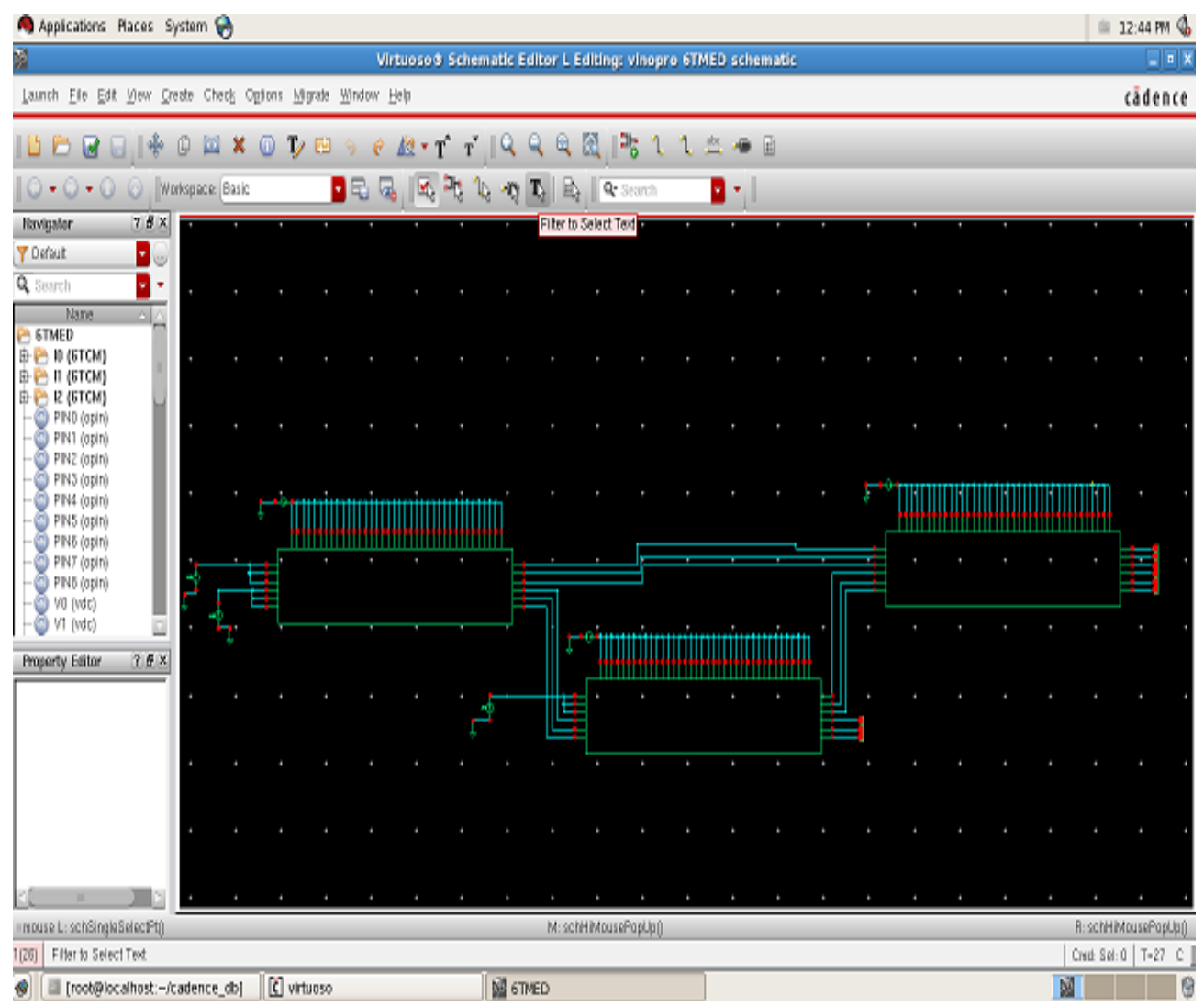

Fig 13: Integration of median filter using 6T full adder

\section{RESULT ANALYSIS}

Here the analysis and the comparison of the median filter using various styles of full adder is shown in table -1based on the simulated waveform and power calculation obtained from the cadence software $0.18 \mathrm{~nm}$ technology.
Table- 1 Comparison of median filters of various style

\begin{tabular}{|l|l|l|}
\hline S no & $\begin{array}{l}\text { Median filter } \\
\text { design }\end{array}$ & $\begin{array}{l}\text { Power } \\
(\mathbf{w})\end{array}$ \\
\hline 1. & $\begin{array}{l}\text { Basic median } \\
\text { filter } 5.959 \mathrm{~m}\end{array}$ \\
\hline
\end{tabular}




\begin{tabular}{|l|l|l|}
\hline 2. & $\begin{array}{l}\text { Median filter } \\
\text { using hybrid } \\
\text { full adder }\end{array}$ & $5.634 \mathrm{~m}$ \\
\hline 3. & $\begin{array}{l}\text { Median filter } \\
\text { using 6T full } \\
\text { adder }\end{array}$ & \\
\hline
\end{tabular}

The powercalculationis done in the following steps. As to obtainthepower ,first the trans analysis of the median filter of various styles are obtained. From the waveform of the trans analysis the power calculation is done using the cadence software $0.18 \mathrm{~nm}$ technology.

The analysis are shown in graphical form by means of chart as follows

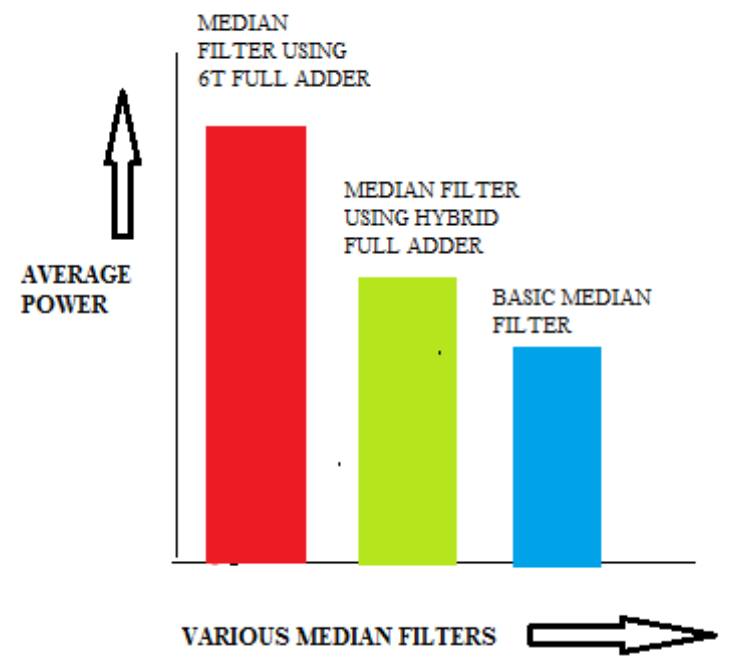

Chart - 1 Power analysis of the median filter of various style

\section{CONCLUSION}

This paper discuss about analysis of various styles of median filter designed using hybrid full adder and 6T full adder. Here the average power consumption of various styles of filters are calculatedusing cadence virtuoso platform. From the power calculation it is observed that median filter designed using 6T full adder consumes less power compared to other median filterswithout much output degradation.

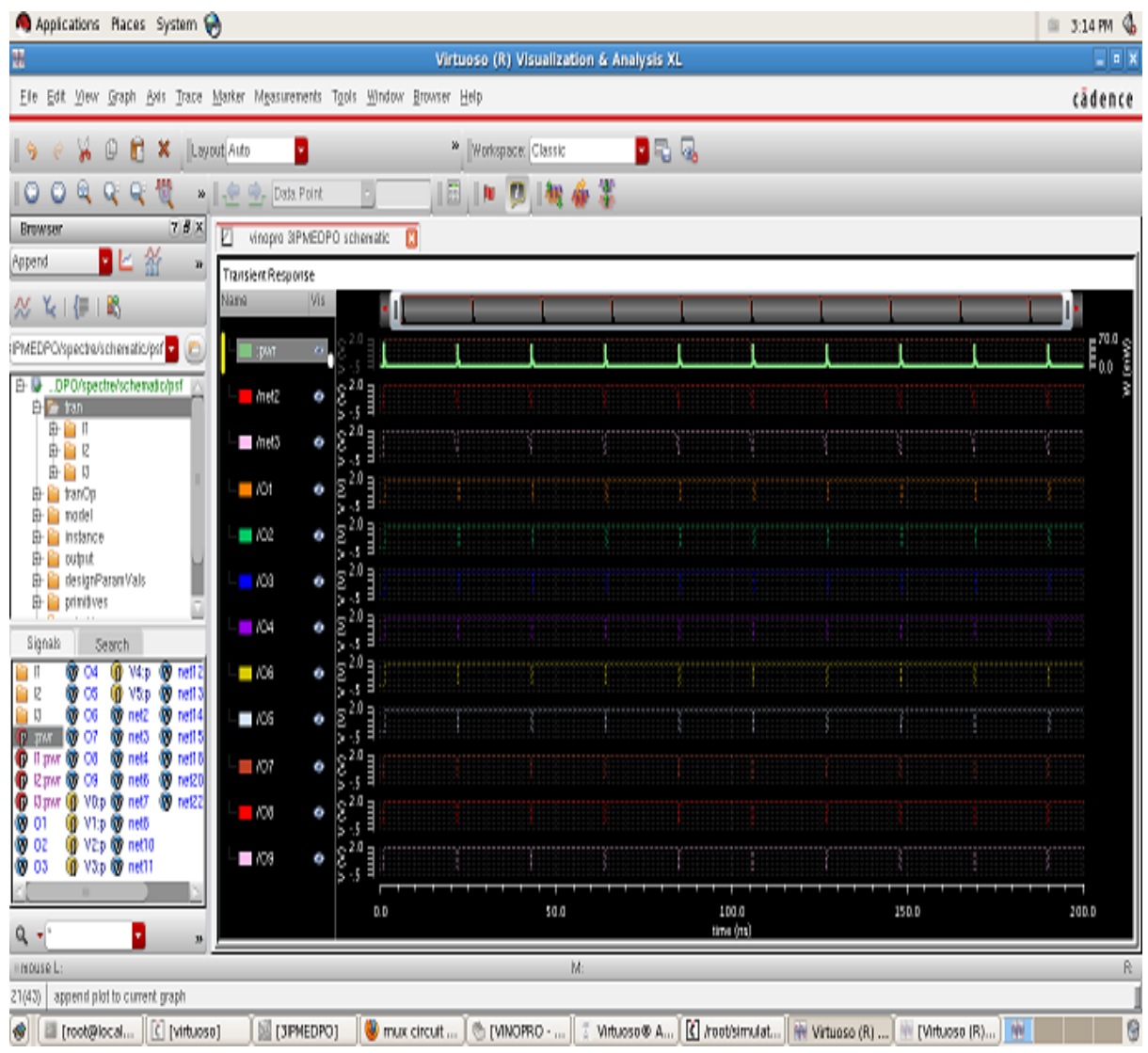

Fig 14: Simulated waveform of basic median filter 


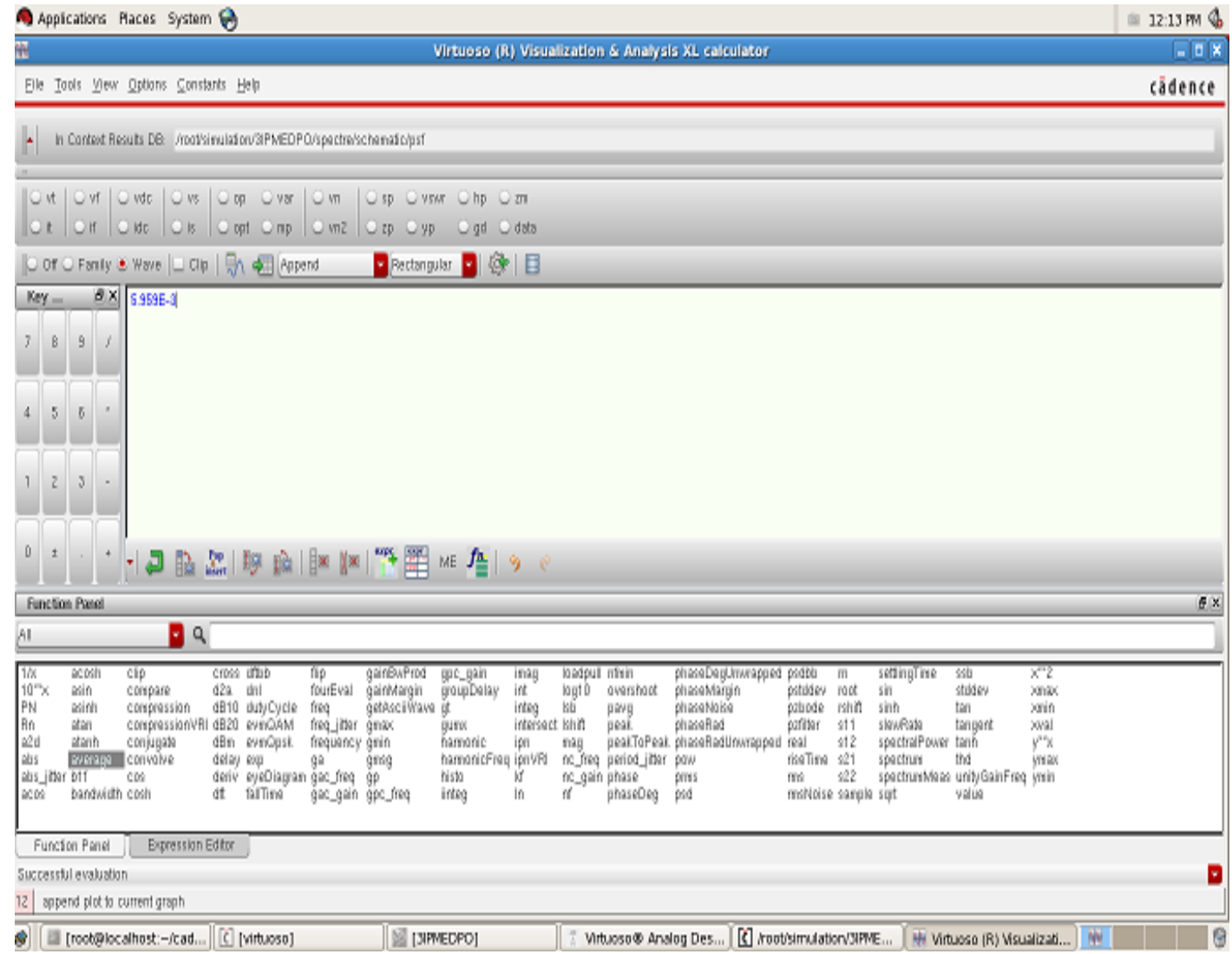

Fig 15: Power calculation of basic median filter

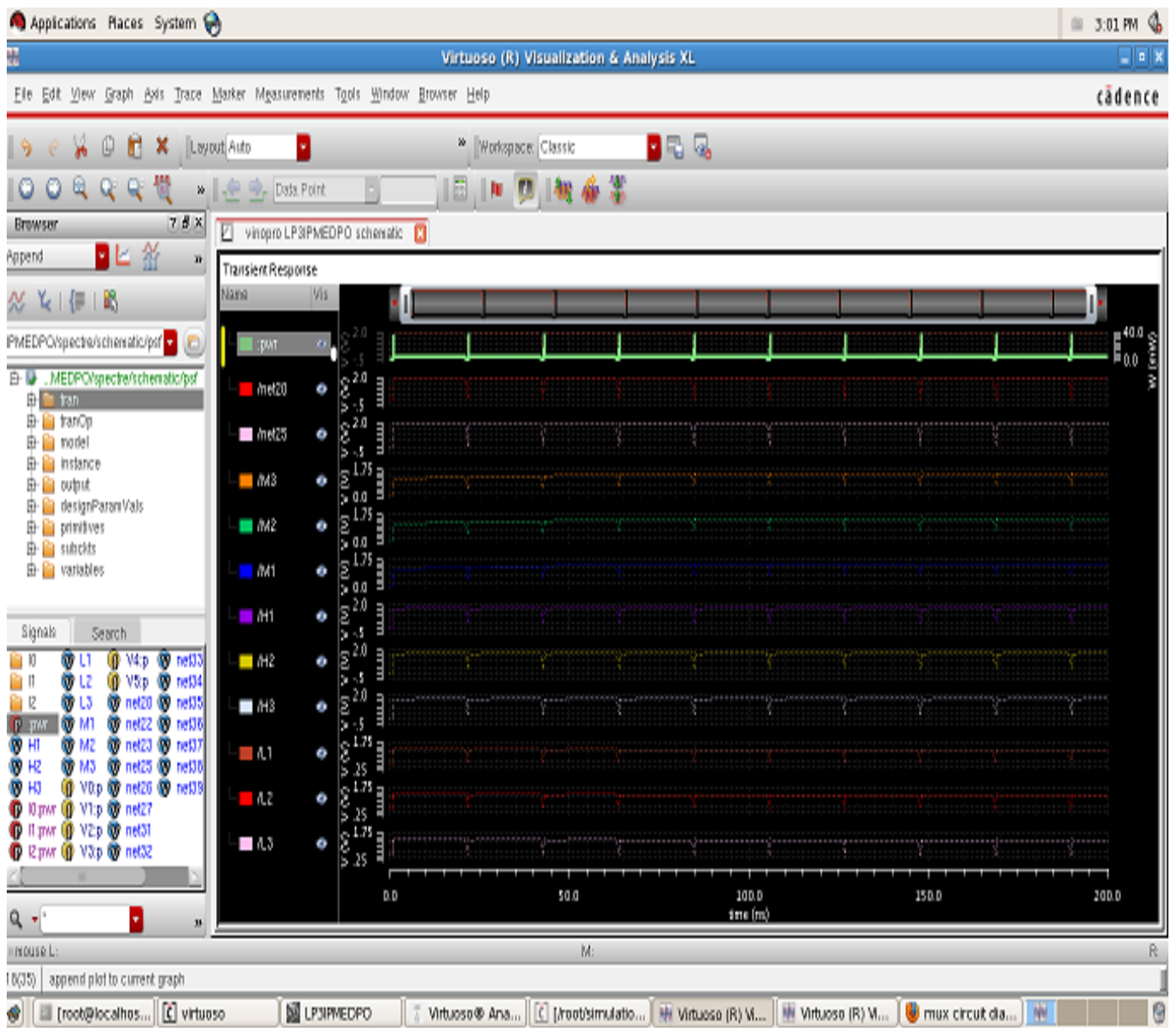

Fig 16: Simulated waveform of median filter using hybrid full adder 


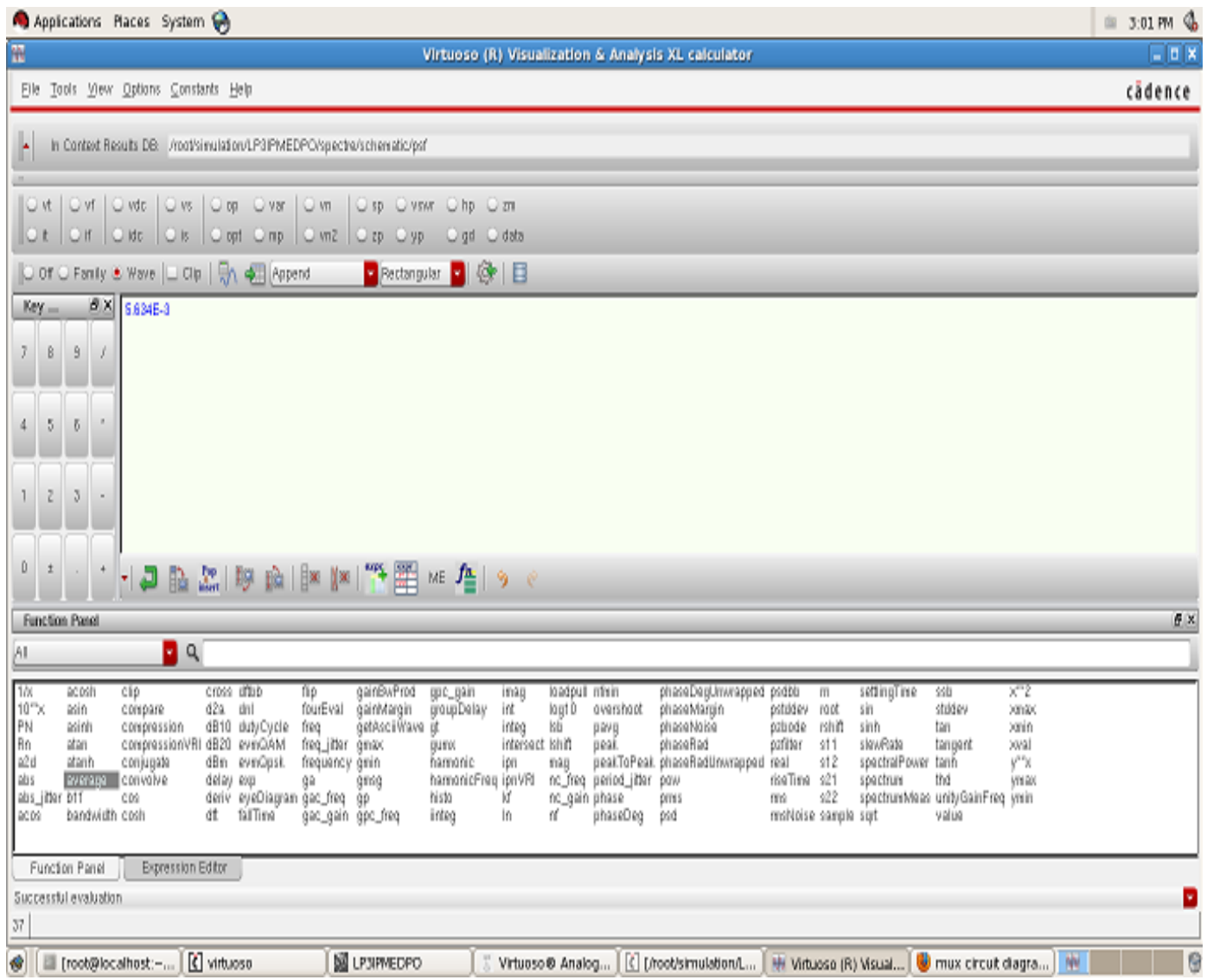

Fig 17: Power calculation of median filter using hybrid full adder

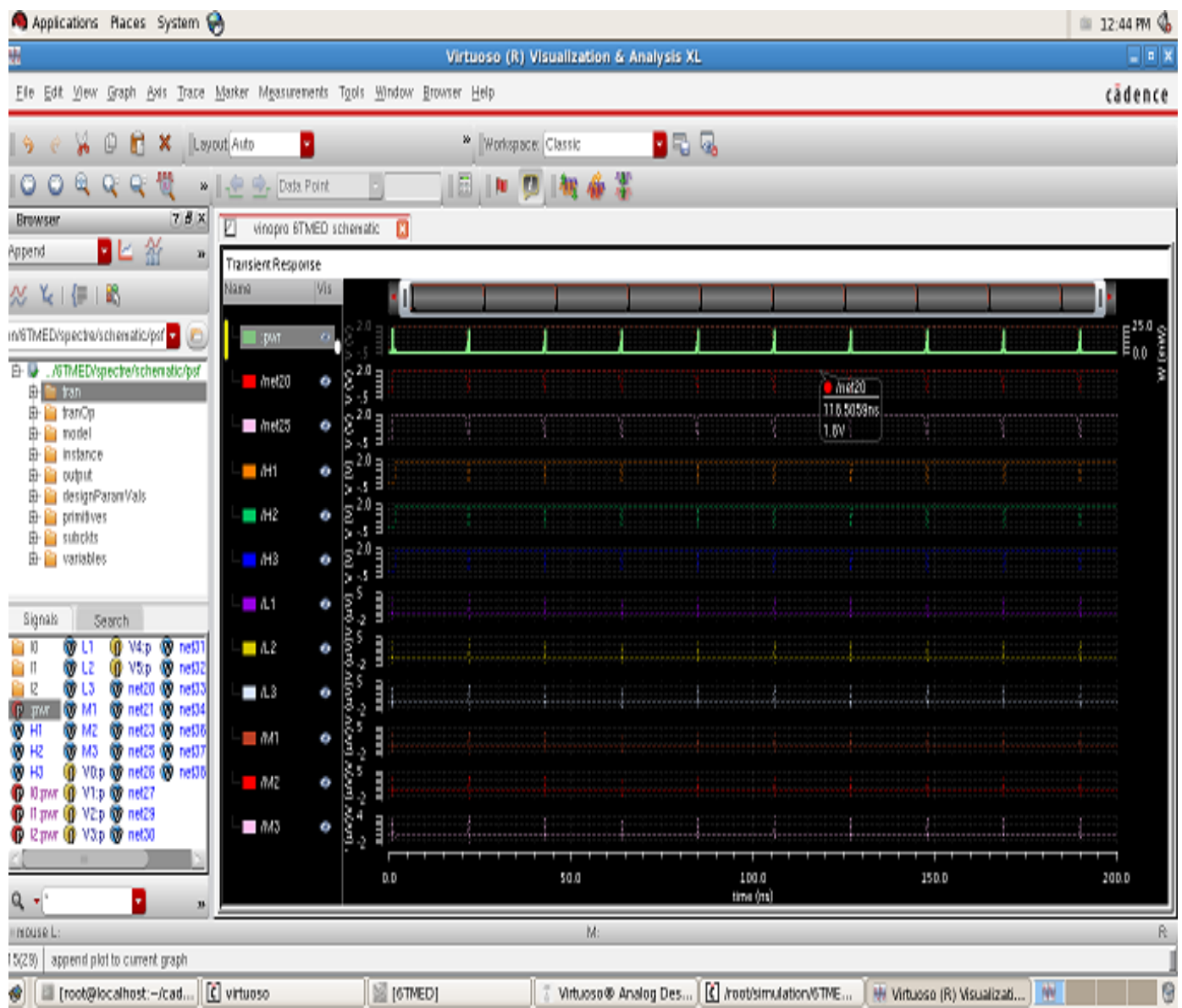

Fig 18: Simulated waveform of median filter using $6 \mathrm{~T}$ full adder 


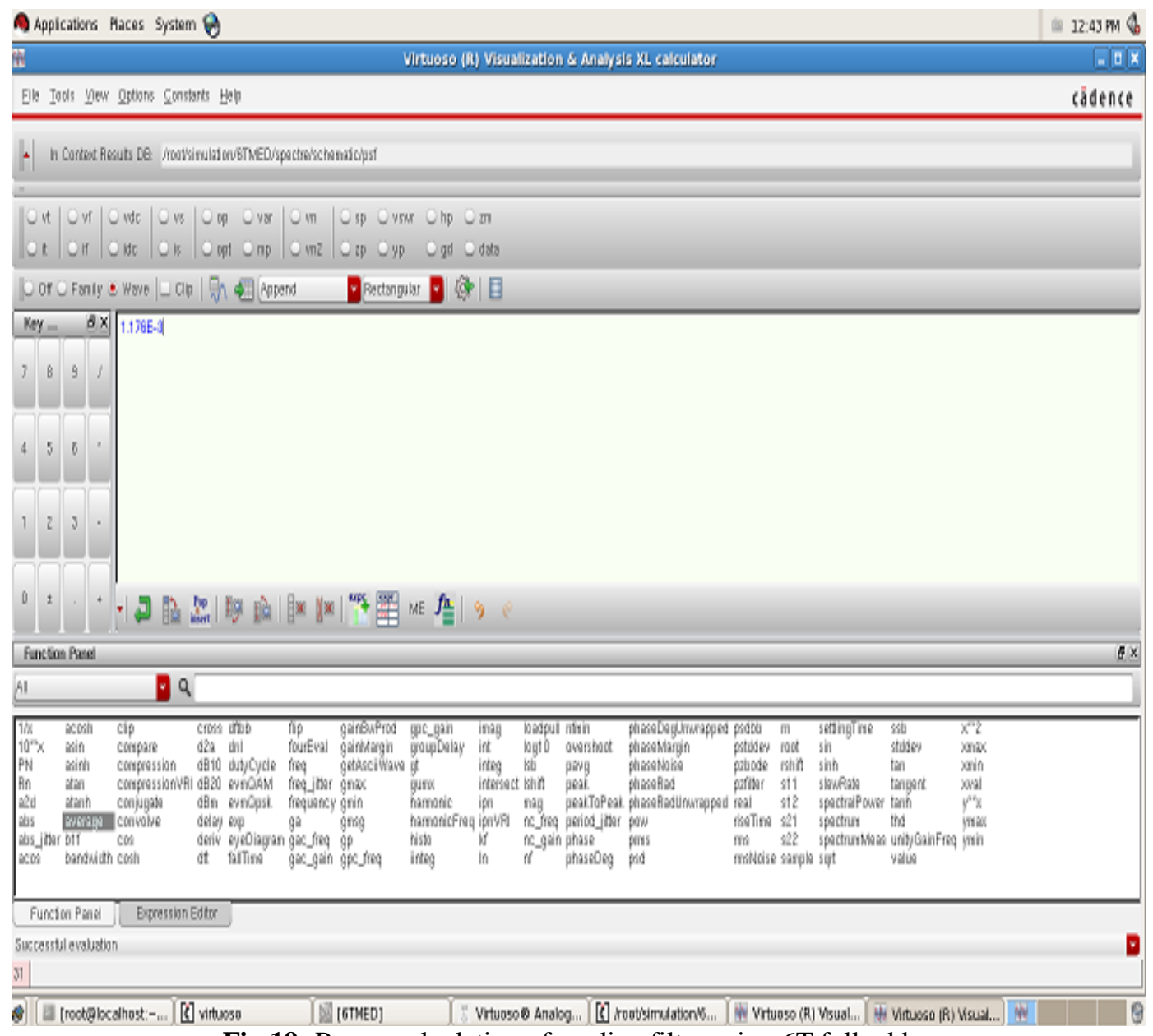

Fig 19: Power calculation of median filter using 6T full adder

\section{FUTURE ENHANCEMENT}

The median filter design using $6 \mathrm{~T}$ full adder will be implemented in MATLAB software in future for testing of noise reduction in the images.

\section{REFERENCES}

[1] Ching-Ta Lu. And Tzu-Chun Chou. (2011), 'Denoising of salt and pepper noise corrupted image using modified directional-weighted-median filter' Taiwan, ROC .

[2] Saroj .k. Meher (2013), 'Recursive and noiseexclusive fuzzy switching median filter for impulse noise reduction' Bangalore, India.

[3] Shi-Jinn Horng., Ling-Yuau Hsu., Tianrui Li. And Muhammad Khurram Khan. (2012), 'Using sorted switching median filter to remove high-density impulse noises' Chengdu, China.

[4] Toh. K.K.V. and Isa. N.A.M. (2010), 'Cluster based adaptive fuzzy based salt and pepper noise removal using adaptive switching median filter' Proc. Eng. 38 2858-2865.

[5] TianBai.,Jieqing Tan., Min Hu. and Yan wang. (2013), 'A novel algorithm for removal of salt and pepper noise using continued fractions interpolation' Hefei, China.
[6] Abdullah Toprak. and InanGuler. (2007), 'Impulse noise reduction in medical images with use of switch mode fuzzy adaptive median filter' Turkey 711- 723 .

[7] Jianjun Zhang. (2009), 'An efficient median filter based method for removing random valued impulse noise' shanghai 200444, China.

[8] Luo. W. (2006), 'An efficient detail-preserving approach for removing impulse noise in images' IEEE signal Process. Lett.13 413 - 416.

[9] WenbinLuo (2006), 'An efficient algorithm for the removal of impulse noise from corrupted images' USA $78228-8534$.

[10] AshutoshPattnaik.,SharadAgarwal. And Subhsis Chand. (2012),'A new and efficient method for removal of high density salt and pepper noise through cascade decision based filtering algorithm' Rourkela, India, Procedia Technology $6108-117$. 